
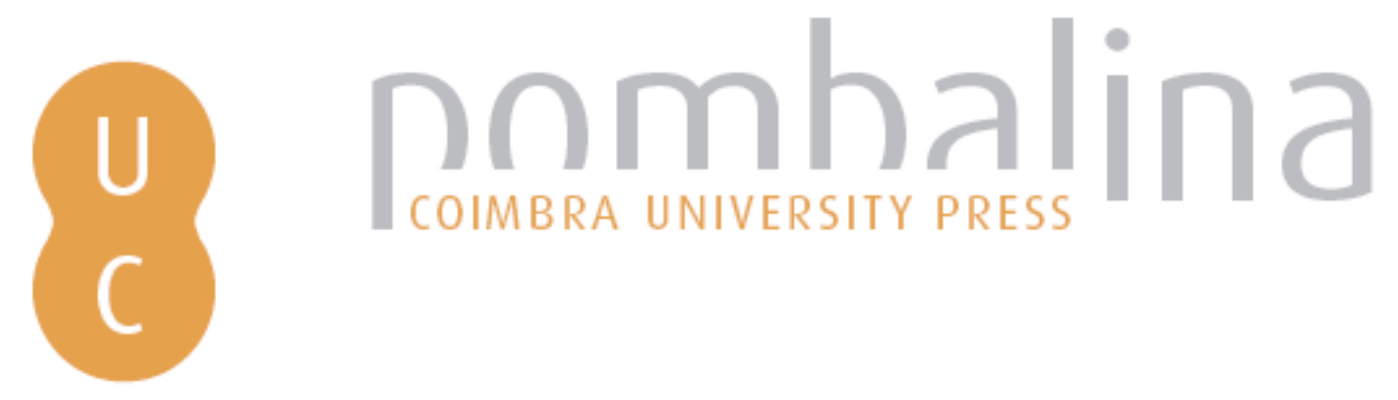

\title{
Toto notus in orbe Martialis: celebração de Marcial 1900 anos após a sua morte
}

Autor(es): $\quad$ Pimentel, Cristina de Sousa; Leão, Delfim F.; Brandão, José Luís L.

Instituto de Estudos Clássicos, Centro de Estudos Clássicos e

Publicado por: Humanísticos; Departamento de Estudos Clássicos, Centro de Estudos Clássicos

URL

persistente: URI:http://hdl.handle.net/10316.2/34626

Accessed : $\quad$ 26-Apr-2023 11:10:21

A navegação consulta e descarregamento dos títulos inseridos nas Bibliotecas Digitais UC Digitalis, UC Pombalina e UC Impactum, pressupõem a aceitação plena e sem reservas dos Termos e Condições de Uso destas Bibliotecas Digitais, disponíveis em https://digitalis.uc.pt/pt-pt/termos.

Conforme exposto nos referidos Termos e Condições de Uso, o descarregamento de títulos de acesso restrito requer uma licença válida de autorização devendo o utilizador aceder ao(s) documento(s) a partir de um endereço de IP da instituição detentora da supramencionada licença.

Ao utilizador é apenas permitido o descarregamento para uso pessoal, pelo que o emprego do(s) título(s) descarregado(s) para outro fim, designadamente comercial, carece de autorização do respetivo autor ou editor da obra.

Na medida em que todas as obras da UC Digitalis se encontram protegidas pelo Código do Direito de Autor e Direitos Conexos e demais legislação aplicável, toda a cópia, parcial ou total, deste documento, nos casos em que é legalmente admitida, deverá conter ou fazer-se acompanhar por este aviso.

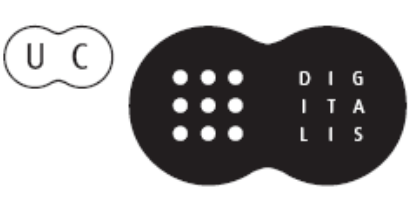




\section{Toto notus in orbe Martialis}

\section{Celebração de Marcial \\ 1900 anos após a sua morte}

Coordenação

Cristina de Sousa Pimentel

Delfim F. Leão

José Luís L. Brandão

Instituto de Estudos Clássicos

Centro de Estudos Clássicos e Humanísticos

UNIVERSIDADE DE COIMBRA
Departamentō de Estudos Clássicos Centro de Estudos Clássicos UNIVERSIDADE DE LISBOA 


\section{Toto notus in orbe Martialis}

\section{Celebração de Marcial 1900 anos após a sua morte}

Quando o poeta Marco Valério Marcial celebrou o seu aniversário pela última vez em Roma, pouco tempo antes de partir de regresso à sua terra natal, Bílbilis, na Hispânia Tarraconense, escreveu:

Ó calendas de Março em que nasci, dia mais belo de todas as calendas, em que até as moças me enviam presentes, pela quinquagésima sétima vez coloco, sobre os vossos altares, bolos e este incensário. A estes anos - mas só se tal voto me for útil ajuntem, por favor, duas vezes nove anos, para que, ainda sem o cansaço de uma excessiva idade, mas com os três arcos do curso da vida completos, eu possa demandar os bosques da elísia moça. Além desta vida de Nestor, nem mais um dia pedirei. ${ }^{1}$

Esse voto, que formulava num momento crucial da sua vida, quando ainda pensava que em Bílbilis iria encontrar alguma felicidade após o desengano da urbe, não veio a realizar-se. Ele não viveu até aos

1 X 24. A tradução é de Paulo Sérgio Ferreira (Marcial, Epigramas. Vol. IV. Tradução de Paulo Sérgio Ferreira, Delfim Ferreira Leão e José Luís Brandão. Introdução e notas de Cristina de Sousa Pimentel. Lisboa, Edições 70, 2004). 
75 anos, como desejou, pois morreu poucos anos depois, teria então os seus 64 .

Corria o ano de 103 ou 104. Ora, em Roma, quando alguém morria, continuava a celebrar-se o seu dies natalis, o dia em que nascera. Foi à luz dessa tradição que desejámos recordar Marcial, nascido nas calendas de Março, quando se perfazem dezanove séculos após a sua morte. Por isso nos reunimos para essa celebração, fazendo afinal apenas aquilo que o poeta tantas vezes fez, relativamente a amigos e protectores que preiteava com genetlíacos; e talvez com esta homenagem tenhamos querido também preencher o silêncio dos seus contemporâneos, que nada disseram ou guardaram sobre ele, à excepção de Plínio-o-Moço, como todos sabemos, e que ainda assim só o evocou à data da sua morte e talvez sobretudo para reproduzir as palavras elogiosas que o poeta sobre ele escrevera.

Desta forma, o Departamento e o Centro de Estudos Clássicos da Faculdade de Letras de Lisboa, o Instituto e o Centro de Estudos Clássicos e Humanísticos da Faculdade de Letras de Coimbra, e a Associação Portuguesa de Estudos Clássicos, em mais uma acção conjunta cuja importância e alcance merece ser sublinhada, pretenderam evocar, em duas Jornadas Científicas (1 de Março de 2004, em Lisboa; 2 de Março de 2004, em Coimbra), aquele que foi o poeta do quotidiano da Roma do séc. I, conhecedor como ninguém das personagens e situações que o caracterizavam, e que, aliando ingenium e ars, soube dar ao epigrama o estatuto e as regras que, depois dele, todos the reconhecem.

Quando pensámos em celebrar as calendas de Março e o poeta dos Epigramas, fizemos, também nós, o que Marcial fazia: chamámos os amigos. Uns vieram com os seus textos, com as palavras que teceram sobre a obra e a época em que ele viveu. Outros - e foram bem mais de uma centena - vieram ouvir as conferências, sem dúvida porque já apreciavam ou porque queriam conhecer melhor a obra do Bilbilitano. Quisemos também assinalar a data com o lançamento do quarto e último volume da tradução dos Epigramas, aquele que contém os Livros $\mathrm{X}$ a XIV, dando conclusão a um projecto que teve o seu início no ano 2000 e resultou igualmente de um concerto de intenções e vontades de docentes das Universidades de Coimbra e Lisboa. E, para encerrar as comemorações, nesses dois dias, o grupo Thíasos, do Instituto de Estudos Clássicos da FLUC, apresentou a dramatização de um conjunto de epigramas, num espectá- 
culo muito bem conseguido e de grande beleza, a que foi dado o título de 'Marcial em traje de cena'.

Pensada a celebração, também fizemos como Marcial e batemos a algumas portas a pedir patrocínio. Algumas, nem se abriram. Outras, abriram-se para nos dizerem que voltássemos em outro dia. Mas, também como acontecia a Marcial, alguns patronos foram generosos e, ainda por cima sem nos fazerem esperar em soberbos e gelados átrios, ouviram o que solicitávamos e deram o seu apoio à singeleza da iniciativa. Como dizia Séneca, um dos primeiros patronos que foi esteio de Marcial na sua chegada à Urbe, a gratidão é um dever a que não devemos faltar, e por isso, em nome das entidades que em boa hora se associaram para realizar o Colóquio, queremos registar o nosso agradecimento à Reitoria da Universidade de Lisboa, à Pró-Reitoria da Universidade de Coimbra, aos Conselhos Directivos das Faculdades de Letras de Lisboa e de Coimbra, ao Instituto Cervantes, à União Latina em Lisboa e ao El Corte Inglês, bem como à Coordenadora do Curso de 'Pós-graduação em Ensino do Latim'.

Trazemos agora a público as Actas do Colóquio que dedicámos a Marcial, para que a reflexão sobre a sua obra, que partilhámos durante dois dias, se alargue aos muitos que venham a lê-la e, em suma, também para que hic ... perpetuo tempore uiuet honor $(\mathrm{I} 88,8)$ e fique a memória desta celebração. As comunicações que se apresentam abordam aspectos como a ligação entre a vida do poeta e os epigramas que escreveu, os reflexos das circunstâncias históricas e sobretudo políticas na sua obra, a presença de linhas temáticas, tão importantes quanto inesperadas num epigramatista (como o amor e a morte), ou debruçam-se sobre considerações de âmbito sociológico e de história das mentalidades. Numa análise centrada em aspectos específicos dos Epigramas, observam-se a perspectiva do poeta relativamente ao teatro, que afinal está presente, ainda que doutra forma, nos seus poemas; o lugar, papel e significado das referências, nos epigramas, aos balnea, e o prisma pelo qual Marcial vê e aprecia os autores, gregos e latinos, que o precederam. Há ainda espaço para analisar a influência de Catulo na produção epigramática de Marcial, e para observar de que modo Marcial e Petrónio trataram o tema do 'novo-rico' e que género de personagens são o Zoilo dos Epigramas e o Trimalquião do Satyricon. Por fim, dois artigos abordam a recepção de Marcial e a forma como a sua obra foi lida, entendida e assimilada, quer pelos 
autores cristãos da Antiguidade tardia e da Idade Média, quer, de modo específico, nos autores espanhóis que, até ao séc. XVII, escreveram em latim.

Com esta publicação pretendemos provar que, de facto, Marcial conseguiu o que dizia poder tentar se tivesse bons mecenas ("erigir obras imorredouras através dos séculos / e arrancar o meu nome às chamas" ${ }^{2}$ ), e lhe foi permitido sobreviver às suas cinzas (VII 44, 7-8: Si ... fas est cineri me superesse meo), ainda que nem sempre a posteridade lhe tenha atribuído o valor que hoje merecidamente se the reconhece.

Os Coordenadores, Cristina de Sousa Pimentel, Delfim F. Leão e José Luís L. Brandão

2 I 107, 5-6. Tradução de José Luís Brandão (Marcial, Epigramas. Vol. I. Tradução de Delfim Ferreira Leão, José Luís Brandão e Paulo Sérgio Ferreira. Introdução e notas de Cristina de Sousa Pimentel. Lisboa, Edições 70, 2000). 